\title{
Recruitment of CD11b/CD18 to the Neutrophil Surface and Adherence-dependent Cell Locomotion
}

\author{
Bonnie J. Hughes, ${ }^{\star}$ J. C. Hollers, Elahe Crockett-Torabi, ${ }^{*}$ and C. Wayne Smith*\$ \\ *Speros Martel Section of Leukocyte Biology, Department of Pediatrics, and ${ }^{\S}$ Department of Microbiology and Immunology, Baylor \\ College of Medicine, Houston, Texas 77030-2399; and ${ }^{\ddagger}$ Department of Pathology, University of Michigan Medical School, Ann Arbor, \\ Michigan 48107-0602
}

\begin{abstract}
Chemotactic stimulation of neutrophils results in translocation of CD11b/CD18 (Mac-1) from intracellular storage pools to the cell surface. Though results from several laboratories indicate that the newly arrived surface Mac-1 is not involved in the adherence induced by the initial stimulus, the present study addresses the hypothesis that this Mac-1 plays a role in subsequent adherence-dependent functions. The response of human neutrophils to changing concentrations of a chemotactic stimulus was evaluated by determining the amount of newly arrived surface Mac-1, and Mac-1-dependent adhesion and locomotion. Small step-wise increases in the concentration of $\mathrm{f}$-MetLeu-Phe (FMLP) resulted in proportional stepwise increases in surface Mac-1 that plateaued within 2-4 min. This newly arrived Mac-1 supported adhesion to protein-coated surfaces only when the cells were exposed to an additional increase in the FMLP stimulus level. Adherence-dependent cellular locomotion was evaluated in chambers that allowed rapid changes in the stimulus concentration. Repeated small increments in the stimulus level at 200-s intervals resulted in significantly longer migration paths than a single-step increase in the stimulus. The results support the hypothesis that small increments in the chemotactic stimulus bring Mac-1 to the cell surface, and this newly mobilized Mac-1 is available for adherence-dependent locomotion with subsequent increases in the concentration of the stimulus. (J. Clin. Invest. 1992. 90:1687-1696.) Key words: adhesion • CD18 • chemotaxis $・$ Mac-1 $・$ neutrophil
\end{abstract}

\section{Introduction}

Neutrophils from patients with CD18 deficiency exhibit little ability to migrate in vitro after chemotactic stimulation. This is especially evident on some protein-coated two-dimensional surfaces (1) and monolayers of endothelial cells $(2,3)$, in that adhesion of chemotactically stimulated neutrophils to artificial surfaces involves CD11b/CD18 (Mac-1) and, on endothelial cells, both Mac-1 and CD1 1a/CD18 (LFA-1) (3). Chemotactic stimulation of normal neutrophils induces Mac-1-dependent adhesion to many protein-coated surfaces (4-7), and re-

Dr. Hollers' current address is Well Stream Health Service, 7600 Chevy Chase Drive, Austin, TX 78752.

Address reprint requests to Dr. Smith, Clinical Care Center, Suite 1130, Texas Children's Hospital, 6621 Fannin, MC-2372, Houston, TX 77030-2399.

Received for publication 2 March 1992 and in revised form 18 June 1992.

J. Clin. Invest.

(C) The American Society for Clinical Investigation, Inc. $0021-9738 / 92 / 11 / 1687 / 10 \quad \$ 2.00$

Volume 90, November 1992, 1687-1696 sults in an increased quantity of CD1 1b/CD18 (Mac-1) on the cell surface $(4,8,9)$. This newly arrived Mac-1 appears to be the result of exocytosis of a subset of secondary granules containing Mac-1 in the perigranular membrane (10-14). Recent evidence indicates that the constitutively expressed Mac-1 is sufficient for the increased adhesion induced by a single chemotactic stimulus (15-19), leaving in doubt the functional significance of the Mac-1 brought to the cell surface by the stimulus. In this report, we address the hypothesis that the newly arrived Mac- 1 can participate in adhesion if the neutrophil subsequently experiences an increase in the chemotactic stimulus.

\section{Methods}

\section{Isolation of neutrophils}

Neutrophils obtained from healthy adult individuals were purified from citrate anticoagulated, dextran-sedimented venous blood samples over Ficoll-Hypaque gradients and were suspended in Dulbecco's phosphate-buffered saline (PBS; Gibco, Grand Island, NY), pH 7.4, containing $0.2 \%$ dextrose as described $(20)$. The isolation steps were carried out at room temperature, and then neutrophils were maintained at $4^{\circ} \mathrm{C}$ in PBS at a concentration of $10^{7} / \mathrm{ml}$.

\section{Monoclonal antibodies ( $\mathrm{mAbs}$ )}

The anti-CD18 mAb, R15.7 (IgG1) (21) and the anti-CD11a mAb, R3.1 (IgG1) (3) were provided by Dr. R. Rothlein (Boehringer Ingelheim Pharmaceuticals, Inc., Ridgefield, $C T$ ) and prepared as previously described (3). The anti-CD11b mAbs, M1/70 (IgG2b) (4), LM2/1 (IgG1) (22), Leu-15 (tagged with phycoerythrin [PE] ${ }^{1}$ ), 904 (IgG1), and 2LPM19c (IgG1, tagged with phycoerythrin PE) were obtained from American Type Culture Collection (Rockville, MD), Dr. T. Springer (Center for Blood Research, Boston, MA), Becton, Dickinson \& Co. (Mountain View, CA), Coulter Immunology (Hialeah, FL), and Dako Corp. (Carpinteria, CA), respectively. The isotype-matched nonbinding control $\mathrm{mAb}$ IgGl was obtained from $\mathrm{Da}$ mon Biotech, Inc. (Needham Heights, MA). All mAbs that bind to neutrophils were titered using flow cytometry (FACScan; Becton Dickinson \& Co.) to determine the concentration that saturated surface binding sites of unstimulated and stimulated cells (i.e., stimulation with $10 \mathrm{nM}$ f-Met-Leu-Phe [FMLP; Sigma Chemical Co., St. Louis, $\mathrm{MO}$ ], $37^{\circ} \mathrm{C}, 15 \mathrm{~min}$ ). In most functional studies, mAbs were initially used at twice the saturating concentration. R15.7 and 904 were biotinylated according to established protocols.

\section{Immunofluorescence flow cytometry}

The quantitation of mAb binding to neutrophils involved the use of indirect and direct labeling with PE. In some instances, the fluorochrome was directly attached to the primary antibody and in others it

1. Abbreviations used in this paper: ACLB, albumin-coated latex beads; $\mathrm{KLH}$, keyhole limpet hemocyanin; PE, phycoerythrin; SA, streptavidin. 
was attached to a $F\left(a b^{\prime}\right)_{2}$ goat anti-mouse second antibody, or streptavidin (SA) for indirect detection of the biotinylated primary antibody binding. Analysis was performed on a FACScan.

The purpose of the first protocol was to assess the extent of up-regulation on Mac-1 after a single-step increase in the concentration of FMLP [FMLP] over a wide concentration range. In order to assess the newly arrived Mac-1, the epitope on Mac-1 recognized by the $\mathrm{mAb}$ used to detect newly arrived Mac-1 was blocked by incubating the neutrophils in the initial [FMLP] and three-fold excess saturating amounts of $\mathrm{mAb}$ for $20 \mathrm{~min}$. The cells were then washed three times in PBS containing the initial [FMLP] to remove the excess mAb. The efficiency of this blocking step was evaluated by exposing the washed neutrophils to biotinylated mAb followed by SA-PE. Though blocking was never found to be completely efficient, binding of biotinylated $\mathrm{mAb}$ was most often reduced by $>90 \%$. If the unlabeled blocking $\mathrm{mAb}$ was not removed, blocking efficiency was usually $>95 \%$. Thus, to assess the newly up-regulated Mac-1, neutrophils with bound unlabeled $\mathrm{mAb}$ were exposed to an increased [FMLP] for $15 \mathrm{~min}$ and then biotinylated $\mathrm{mAb}$ was added for $15 \mathrm{~min}$. Cells were then washed twice in PBS, exposed to SA-PE for $15 \mathrm{~min}$, then prepared for flow cytometry using the Becton Dickinson lysing reagent, followed by fixation in $1 \%$ paraformaldehyde. Because the level of binding of the biotinylated $\mathrm{mAb}$ in these experiments represented a combination of newly upregulated sites and those exposed by washing off some of the blocking $\mathrm{mAb}$, experiments consistently contained controls to assess the efficiency of blocking. Two biotinylated mAbs were used in these experiments, 904 (anti-CD11b) and R15.7 (anti-CD18).

A second protocol was used to assess the kinetics of Mac-1 mobilization. Neutrophils were suspended for $3 \mathrm{~min}$ at $37^{\circ} \mathrm{C}$ in PBS containing the primary antibody (Leu 15-PE, or 2LPM19c, both anti-CD11b) at saturating concentrations. This preparation was directly sampled in the flow cytometer to determine the baseline level of fluorescence of these viable cells. The stepwise increases of chemotactic stimulus were then added at 10-min intervals and the suspension was sampled to determine the changes in fluorescence by analyzing 3,000 viable cells at 1-min intervals. Temperature was maintained at $37^{\circ} \mathrm{C}$ using a heat block, and cells were maintained in suspension by periodic gentle vortexing.

The following procedure was used to estimate the number of binding sites for antibodies 904 and R15.7 on the neutrophil surface. Simply cellular microbeads (Flow Cytometry Standards Corp., Research Triangle Park, NC) were stained in parallel with neutrophils. These $8-\mu \mathrm{m}$ diam beads have covalently bound goat anti-mouse antibodies on their surface with a known number of binding sites per bead. Analysis was performed using a FACScan flow cytometer calibrated with quantitative PE microbead standards (Flow Cytometry Standards Corp.) to determine the fluorescence/protein ratio. By using this ratio, the number of binding sites for these antibodies on neutrophils could be estimated (20).

\section{Adhesion assays}

Protein-coated glass. A previously published assay was used $(23,24)$ that involves coating $25-\mathrm{mm}$ round coverglasses with keyhole limpet hemocyanin ( $\mathrm{KLH}$; Sigma Chemical Co.) for $30 \mathrm{~min}$ at $37^{\circ} \mathrm{C}$. The coverglasses were washed in PBS and mounted in adhesion chambers (23). Isolated neutrophils suspended in PBS were allowed to settle onto this surface for $500 \mathrm{~s}$, and the chamber was inverted for an additional $500 \mathrm{~s}$. The percentage of neutrophils remaining attached to the proteincoated surface was determined as previously described (23). The chemotactic tripeptide, FMLP, used to stimulate adhesion was added immediately before the neutrophils were injected into the adhesion chamber, and remained with the neutrophils throughout the assay.

Albumin-coated latex beads $(A C L B)$. Latex beads $(0.6 \mu \mathrm{m}$, Sigma Chemical Co.) were coated with human serum albumin (Sigma Chemical Co.) and used to evaluate cell adherence as previously described (23). Neutrophils were exposed to sequential, carefully timed stepwise changes in [FMLP] in order to not only stimulate adhesion of ACLB to the neutrophil surface, but to stimulate transport of the bound ACLB to the uropod of polarized cells (24). The first stimulus ( 1 nM FMLP) added in the presence of ACLB for $5 \mathrm{~min}$ at $37^{\circ} \mathrm{C}$. The second stimulus ( $5 \mathrm{nM}$ FMLP) was added in the presence or absence of $\mathrm{mAbs} 5 \mathrm{~min}$, $37^{\circ} \mathrm{C}$. The third stimulus ( $10 \mathrm{nM}$ FMLP) was added and cells were incubated $20 \mathrm{~s}, 37^{\circ} \mathrm{C}$ before being fixed in $1 \%$ glutaraldehyde. In this protocol, the first stimulus has been shown previously (24) to promote adhesion of ACLB, the second stimulus to induce transport of bound ACLB to the uropod, and the third stimulus to promote binding of new ACLB to the highly ruffled regions of the polarized cell opposite the uropod. Adding the mAbs during the second stimulus allowed evaluation of the effects of the mAbs on ACLB binding induced by the third stimulus. A visual count of the numbers of beads bound to each cell was made using a Leitz differential interference contrast microscopy with a $\times 100$ oil objective.

\section{Adherence-dependent neutrophil migration}

Glass parallel plate flow chambers (20) (depth of $500 \mu \mathrm{m}$ ) were filled with $2 \%$ human serum in PBS for 2 min and washed by exchanging the volume of the chamber $(\approx 50 \mu \mathrm{l})$ three times with PBS. This procedure for coating glass has been shown previously to produce a marked reduction in the adhesion of isolated human neutrophils suspended in PBS without protein supplements, and a spherical cell shape for those cells that adhere (23). Neutrophil adherence was shown to be increased by chemotactic stimulation (23-27), and this increase was found to be largely Mac-1 dependent (4). Neutrophils suspended in PBS or a given [FMLP] were introduced into inverted chambers and allowed to settle onto the upper wall (i.e., ceiling) of the chamber. The chambers were then turned upright and nonadherent cells were removed by exchanging the chamber volume with PBS containing the initial [FMLP]. Subsequent exchanges of the chamber volume allowed exposure of adherent cells to stepwise increases in [FMLP]. This procedure assured that cell migration resulting from the chemotactic stimulus was adherencedependent in that the cells hanging from the chamber ceiling could only migrate if they remained attached to this surface. For the determination of migration tracks (paths and lengths) 25-30 neutrophils per chamber were analyzed on videotapes of each experiment. Paths were traced from a video monitor screen during replay of the videotapes, and distance migrated over the observation interval (10-15 $\mathrm{min}$ ) was determined by the distance traversed by the uropod of each cell (or to the point where the cell detached from the protein-coated surface). Mean path lengths were calculated for each experiment and the mean $\pm S D$ was calculated for the replicates of the experiment. In some instances, outlines of cells were traced at $\sim 100$-s intervals to provide representative figures of neutrophil behavior. The number of neutrophils per five $\times 400$ microscopic fields was determined at the beginning and at $400,1,200$, and 2,000 $\mathrm{s}$ to assess percentage of cells remaining attached.

\section{Scanning electron microscopy}

Cells in suspension or attached to protein-coated glass were fixed in cold $1.0 \%$ glutaraldehyde in $0.1 \mathrm{M}$ PBS for $2 \mathrm{~h}$, then dehydrated in a graded ethanol series. Cells were critical-point dried, and preparations mounted on aluminum stubs, sputter-coated with $20-30 \mathrm{~nm}$ of gold, and examined in a scanning electron microscope (International Scientific Instruments, Inc., Santa Clara, CA).

\section{Results}

Evaluation of newly arrived surface Mac-1 in cell adhesion. $\mathrm{KLH}$-coated glass was chosen as a substrate because we have previously found that contact with this surface does not appear to directly activate the neutrophil (24), and that adhesion of neutrophils to this surface requires chemotactic stimulation and is Mac-1 dependent (24). The mean adherence of unstimulated neutrophils to this surface was less than five cells per five 


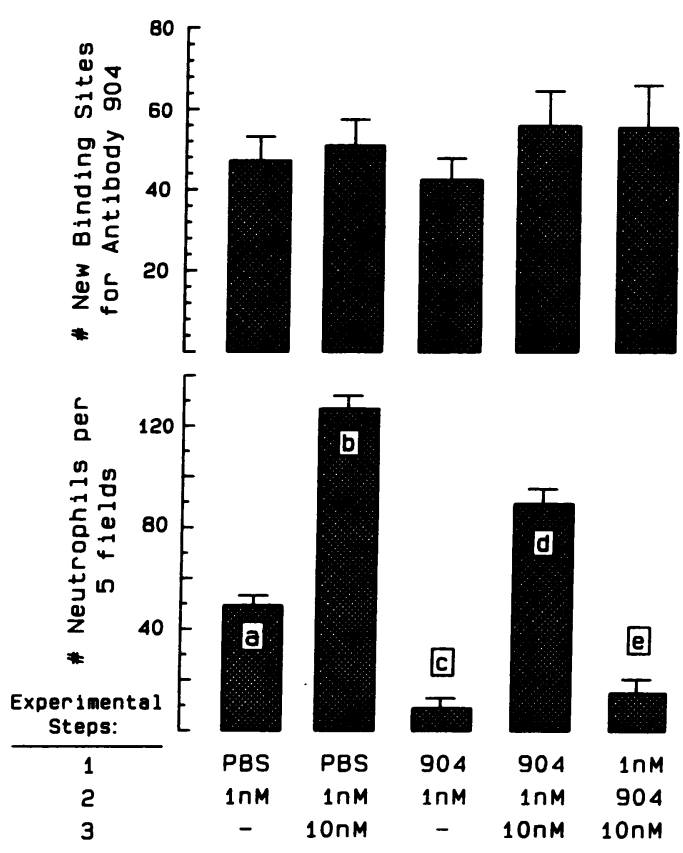

Figure 1. Newly arrived surface Mac-1 and the adhesion of neutrophils to KLH-coated glass. The results of five experimental conditions (labeled $a-e$ ) are shown, each involving three incubation steps. In the first incubation, isolated neutrophils were suspended in PBS, mAb $904(10 \mu \mathrm{g} / \mathrm{ml})$, or $1 \mathrm{nM}$ FMLP for $15 \mathrm{~min}$ at room temperature, and then washed in PBS to remove the unbound mAb 904. In the second incubation, these neutrophils were exposed to $1 \mathrm{nM}$ FMLP or $\mathrm{mAb} 904$ for $15 \mathrm{~min}$, and then without washing, cells were either maintained in $1 \mathrm{nM}$ FMLP or the concentration of FMLP was increased to $10 \mathrm{nM}$ immediately before being injected into the adhesion chambers (third incubation). Upper panel: the number of new binding sites for mAb 904 were determined in aliquots of neutrophils taken 15 min after stimulation of the cells with $1 \mathrm{nM}$ FMLP. These values are expressed as the number of new binding sites for $\mathrm{mAb} 904$ (mean in thousands with SEM, $n=3$ ). None of the results were significantly different. Lower panel: adhesion to KLH-coated glass was determined after a 500-s contact time with the protein-coated glass surface, and is plotted as number of neutrophils per five $\times 40$ microscopic fields ( mean \pm SEM, $n=8$ ). The level of adhesion represented by the second bar is $49 \%$ of the neutrophils originally contacting the $\mathrm{KLH}$-coated surface. Baseline adhesion (i.e., that in the absence of any chemotactic stimulus) was $<3 \%$ ( $n=45$, data not shown). Statistical evaluations: Experimental condition $a, P<0.01$ compared to baseline adhesion (without chemotactic stimulation); $b, P<0.01$ compared with the results in $a ; c$, not significantly different from baseline adhesion; $d, P<0.01$ compared with results in $c ; e$, not significantly different from $c$.

microscopic fields. To assess the ability of newly mobilized Mac-1 to support adhesion, constitutive Mac-1 was blocked with $\mathrm{mAb} 904$, an anti-CD1 $1 \mathrm{~b}$ antibody previously shown to block Mac-1 dependent adhesion (24). To accomplish this, unstimulated neutrophils were incubated with 904 for $15 \mathrm{~min}$, and then washed to remove the unbound $\mathrm{mAb}$ before the initial stimulation with the chemotactic factor. In contrast to control cells where constitutive Mac-1 was not blocked by 904 , 904-blocked cells exhibited a level of adherence that was not significantly different from unstimulated neutrophils (Fig. 1, lower panel, experimental conditions $a$ and $c$ ). This failure to increase adherence occurred even though the increase in binding sites for 904 after the initial chemotactic stimulus was not significantly different for both control and 904-pretreated cells (Fig. 1, upper panel). Thus, as other investigators have concluded, it appeared that the newly arrived Mac-1 did not participate in adhesion. However, cells on which constitutive Mac-1 had been blocked by mAb 904 (Fig. 1, experimental condition d) increased their adhesiveness as well as normal cells (Fig. 1, experimental condition $b$ ) when exposed to an increase in the [FMLP]. These results are consistent with the interpretation that Mac-1 arriving at the cell surface during the first ( $1 \mathrm{nM}$ ) FMLP stimulus period was stimulated to participate in the adhesion induced by the second ( $10 \mathrm{nM}$ ) FMLP stimulus. This interpretation is further supported by the finding that neutrophils exposed to 904 after the initial $1 \mathrm{nM}$ stimulus exhibited no increase in adhesion following the $10 \mathrm{nM}$ stimulus (Fig. 1, experimental condition $e$ ).

The experiments shown in Fig. 1 and described above were repeated ( $n=4)$ with the exception that mAb R15.7 (antiCD18 previously shown to block Mac-1 dependent adhesion) $(21,24)$ was substituted for mAb 904 . R15.7 produced the same statistically significant effects as 904 and revealed the same level of new binding sites following the chemotactic stimulations (data not shown).

Surface distribution of newly expressed adhesion sites. ACLB assay was used to assess surface distribution of Mac-1dependent adhesion sites on neutrophils. As shown in previous studies $(25,26)$, unstimulated neutrophils in suspension bind few ACLB. However, when exposed to a single (first) stimulus of FMLP neutrophils demonstrate bipolar morphology, and avidly bind ACLB in a generalized and apparently random distribution. With a second stimulus of $5 \mathrm{nM}$ FMLP the ACLB move to the uropod. A third stimulus of $10 \mathrm{nM}$ FMLP creates new binding sites at the anterior region of the cell as evidenced by bead binding to this area of membrane ruffling (Fig. 2). Over a period of $5 \mathrm{~min}$ these ACLB move to the uropod. In previously published studies we have shown that with a single stimulus of FMLP in the presence of either anti-CD18 or antiCD1 lb both the percentage of cells binding ACLB and the numbers of beads bound per cell were greatly inhibited (4). In those studies anti-CD1 la had no affect on binding, indicating that the binding of ACLB is Mac- 1 dependent. In the present study, the mAbs R15.7 (anti-CD18), LM2/1 (anti-CD11b), 904 (anti-CD11b), M1/70 (anti-CD11b), R3.1 (antiCD1 la), or a nonbinding IgGl were introduced coincident with the second FMLP stimulus ( $5 \mathrm{nM}$ ) in the protocol given above, and retained with the cells and ACLB through the third stimulus ( $10 \mathrm{nM})$. Thus, the antibodies were available to block binding after ACLB binding was induced by the first ( $1 \mathrm{nM}$ ) FMLP stimulus, the objective being to determine if these mAbs would block subsequent ACLB binding induced by the second and third levels of FMLP stimulation. Because the ACLB that bound after the first ( $1 \mathrm{nM}$ ) stimulus move to the uropod of the cell, only ACLB on the body or lamella of the cell (Fig. 2) were enumerated. These would reflect beads bound as a result of the subsequent chemotactic stimuli. Anti-Mac-1 antibodies almost completely inhibited this ACLB binding (Fig. 2). In contrast, mAb R3.1 (anti-CD1 la) and IgG1 (nonbinding control) were without effect.

These experimental conditions were used to address again the question of whether newly mobilized Mac-1 can participate 

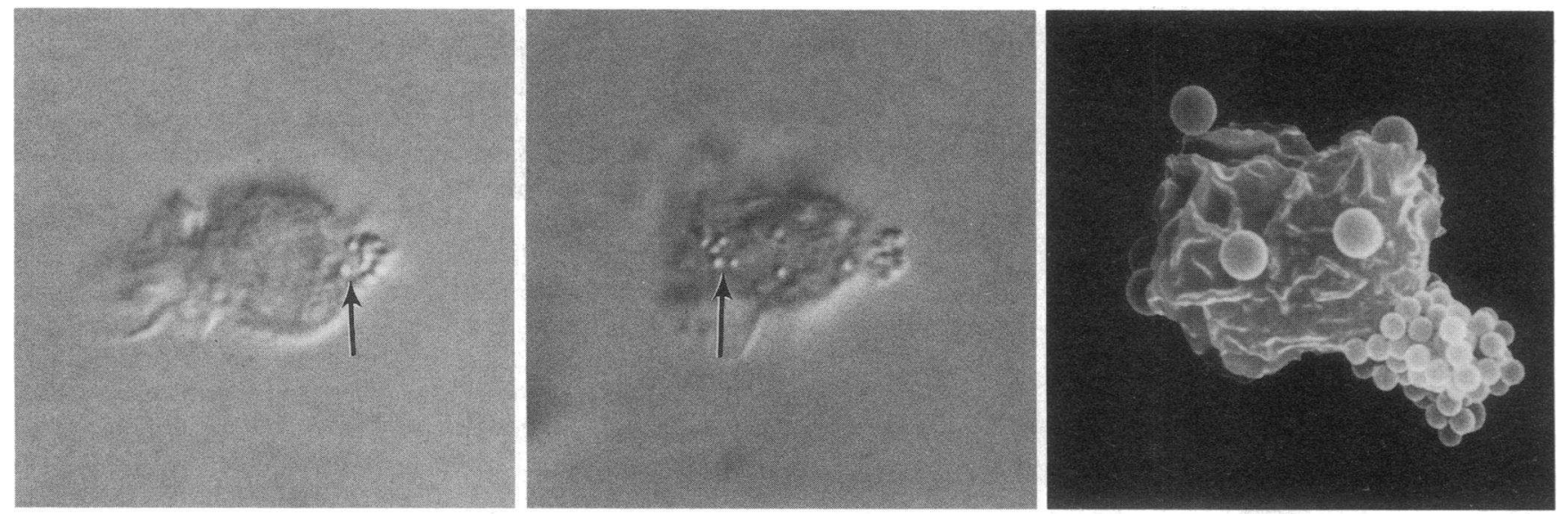

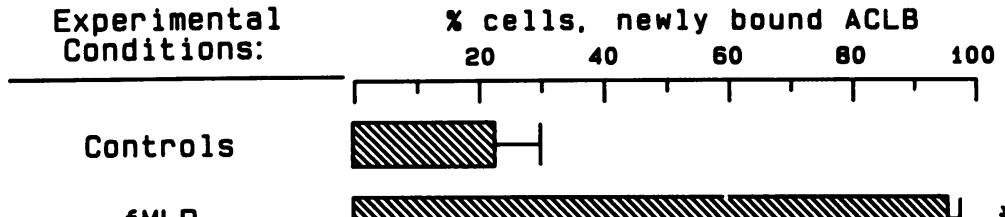

fMLP, R15.7

fMLP. LM2/1

fMLP, $M 1 / 70$

fMLP. R3.1

fMLP. IgG1
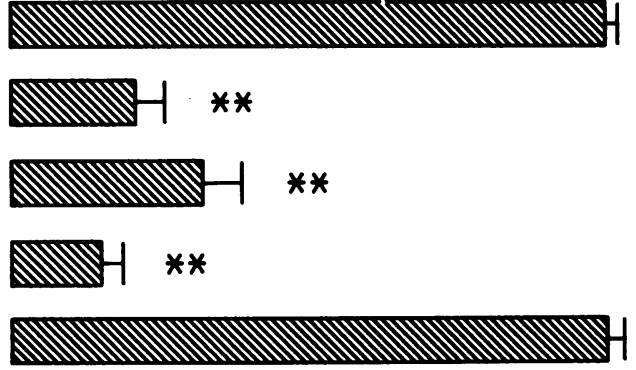

Figure 2. Top: the distribution of ACLB on stimulated neutrophils. Isolated neutrophils were suspended in PBS containing ACLB ( $0.6 \mu \mathrm{m}$ diameter $)$ and $1 \mathrm{nM}$ FMLP for $5 \mathrm{~min}$ at $37^{\circ} \mathrm{C}$. The [FMLP] was then increased to 5 $\mathrm{nM}$ for an additional $15 \mathrm{~min}$ before the cells were fixed in glutaraldehyde. Under differential interference contrast microscopy cells were examined for surface-bound ACLB. Greater than $90 \%$ were polarized with most of the ACLB clustered on the uropod (arrow), as depicted by the cell in the left photograph. Additional cells were treated the same with the exception that a third concentration of FMLP ( $10 \mathrm{nM}$ ) was introduced for $20 \mathrm{~s}$ before the fixation in glutaraldehyde. Greater than $90 \%$ of these cells had five or more beads bound to sites other than the uropod (arrow), as illustrated by the cell in the middle photograph. Additional cells were processed for scanning electron microscopy to confirm that the newly bound ACLB were on the cell surface. Larger ACLB (1.0 $\mu \mathrm{m}$ in diameter) were introduced coincident with the

third stimulus using techniques previously reported (25) in order to identify those beads that adhered as a result of the third chemotactic stimulus. A representative cell is shown in the right photograph. Bottom: the results of including $\mathrm{mAbs}(10 \mu \mathrm{g} / \mathrm{ml})$ in this protocol are shown in the bar graph. The results are derived from four separate experiments with $>100$ cells being evaluated for each experimental condition in each experiment, and results are plotted as mean $\pm \mathrm{SD} .{ }^{*} P<0.01$ compared with control; ${ }^{* *} P<0.01$ compared with cells receiving the third FMLP stimulus without added mAb. LM2/1 and M1/70 are anti-CD11b mAbs; R15.7, anti-CD18; R3.1, anti-CD11a.

in adhesion. Constitutively expressed Mac-1 was blocked by preincubation with $\mathrm{mAbs}$ as described above. The neutrophils were washed to remove unbound $\mathrm{mAb}$, and then stimulated with 2 nM FMLP. The percentage of cells binding ACLB was determined as described above. A value $(18.3 \pm 4.7 \%, n=9)$ was obtained that was not significantly different from those values shown in Fig. 2 where the blocking mAbs were retained with the cells during exposure to ACLB. However, when these cells were exposed at $5 \mathrm{~min}$ after the initial FMLP stimulus to a $10 \mathrm{nM}$ stimulus, the percentage of cells with newly bound ACLB was $72.6 \pm 5.3(n=9, P<0.01)$.

Stepwise increases in concentration of FMLP result in stepwise increases of surface Mac-1. The results using ACLB are consistent with the experiments in Fig. 1, and further support the interpretation that Mac-1 arriving at the cell surface during the initial stimulus was stimulated to participate in the adhesion induced by the second stimulus. Such a mechanism might play a role in cell locomotion if neutrophils repeatedly experienced changes in the concentration of a chemotactic factor (i.e., Mac-1 brought to the surface by a prior stimulus would function in adhesion with the next stimulus). This would require repeated activation of the adhesiveness of surface Mac-1, and translocation of additional Mac-1 to the cell surface in response to very small changes in the chemotactic stimulus. In that the results presented above followed large steps in [FMLP], we sought to determine if Mac-1 up-regulation would follow small stimulus increments.

In these studies neutrophils were exposed to a given [FMLP] for $15 \mathrm{~min}$ in the presence of anti-Mac-1 mAb. Cells were then washed in PBS containing this concentration of FMLP in order to remove the unbound $\mathrm{mAb}$ without changing the [FMLP]. These cells were then exposed to an increase in [FMLP] for $15 \mathrm{~min}$. The newly up-regulated Mac-1 was detected using the same mAb biotin labeled, followed by SA-PE. The results of such studies over a wide concentration range are shown in Fig. $3 \mathrm{~A}$. Fig. $3 \mathrm{~B}$ illustrates the effect of increasing the size of the second step on the magnitude of the new surface Mac-1. Leukocytes isolated from four donors were studied us- 

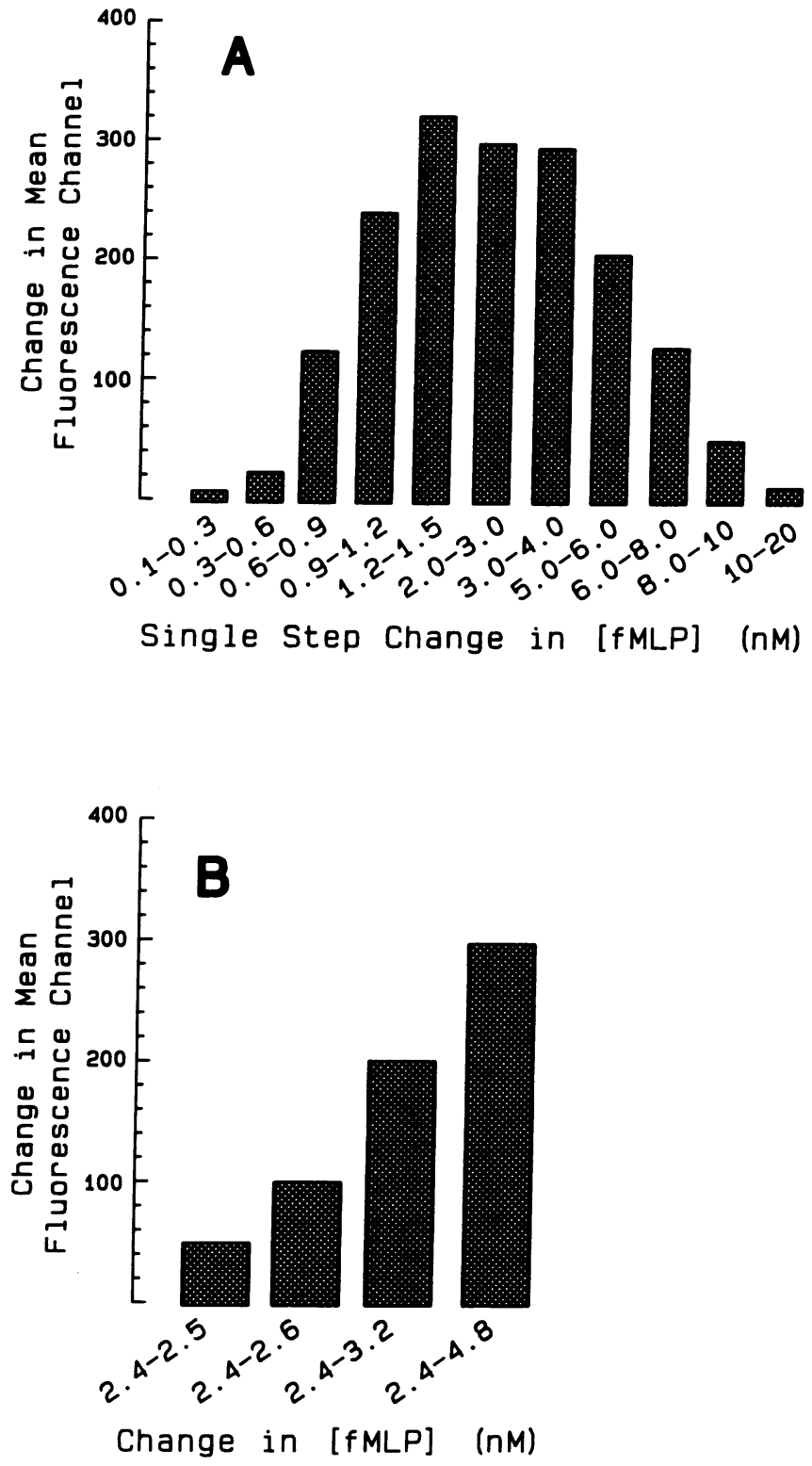

Figure 3. Effect of a single-step change in [FMLP] on the binding of $\mathrm{mAb} 904$ to isolated human neutrophils. Isolated neutrophils were suspended in PBS containing the concentration of FMLP shown as the initial value in the pair of concentrations under each bar for 15 $\mathrm{min}$ at room temperature in the presence of $\mathrm{mAb} 904$. The cells were then washed in PBS containing this concentration of FMLP in order to remove the unbound $\mathrm{mAb}$. Cells were then resuspended in the second concentration of FMLP, and incubated for an additional 15 $\mathrm{min}$. The ability of this second stimulus to increase surface binding sites for 904 was evaluated using biotinylated 904 and SA-labeled PE. In order to distinguish only that Mac-1 up-regulated by the new stimulus, parallel controls were prepared without increasing the [FMLP]. The values plotted are the difference between these controls and the test condition where [FMLP] was increased. Thus, changes in $\mathrm{mAb}$ binding resulting simply from the incubation conditions were subtracted out, leaving only changes induced by the new level of FMLP. The mean increase in cell-associated PE fluorescence is plotted. These data are the mean of duplicate determinations using neutrophils from a single donor and are representative of results from four separate experiments. $(A)$ Increases in Mac-1 after single steps in [FMLP] from different levels. $(B)$ Increases in Mac-1 after increasing steps in [FMLP] from the same initial level. ing these protocols. In each case, the extent of Mac- 1 mobilized by the second stimulus was greatest when the initial [FMLP] was below $\sim 8 \mathrm{nM}$. Above this level, little new Mac-1 could be detected following the second stimulus level. When the primary [FMLP] was below $\sim 6 \mathrm{nM}$, the amount of Mac-1 mobilized by the second stimulus appeared to be proportional to the size of the change in [FMLP]. This was easily shown in experiments (e.g., Fig. $3 B$ ) where the initial [FMLP] was the same and the second stimulus was increased. However, the sensitivity of the neutrophils to a change in [FMLP] appeared to diminish as the primary stimulus level was increased. For example, a change from 1.2 to $1.5 \mathrm{nM}$ resulted in a greater increase in Mac-1 than from 5.0 to $6.0 \mathrm{nM}$.

Kinetics of stepwise increases in surface Mac-1. To study the kinetics of sequential stepwise increases in the [FMLP] on the surface expression of Mac-1, we used directly labeled antiCD11b mAbs Leu-15 or 2LPM19c, and FMLP concentrations within what appeared in Fig. $3 A$ to be the optimum range for up-regulating Mac-1. Cells were repeatedly exposed to changes in [FMLP], each step resulting in rapid increases in surface Mac-1 (Fig. 4). In experiments with neutrophils from five donors, increases in Mac-1 after each step were rapid in the first 2 $\mathrm{min}$ and then appeared to plateau by 3-4 min.

Evaluation of Mac-1-dependent cell locomotion. In order to evaluate the effect of stepwise increases in [FMLP] on adherence-dependent cell locomotion, neutrophils were allowed to attach to the upper wall (i.e., ceiling) in a parallel plate flow chamber. This glass surface was coated with serum before introduction of the neutrophils. The attached cells were observed under phase-contrast optics, and their behavior recorded on videotape for subsequent analysis. To expose the cells to changes in [FMLP], the chamber volume was replaced with PBS containing the specified [FMLP]. As seen in previous studies (25), a single step in [FMLP] to a level that stimulated shape change (e.g., 1 nM FMLP) induced migration for a short distance. Then progressive detachment ensued until many cells were simply hanging by the tip of the uropod (Fig. 5). If, however, the attached neutrophils were exposed to progressive steps in the [FMLP], they remained attached and continued to migrate (Fig. 6). As shown in Fig. 7, step increases of $10 \%$ (i.e., the new [FMLP] was $110 \%$ of the previous [FMLP]) introduced into the chamber at 200-s intervals significantly increased the percentage of neutrophils that remained attached, and significantly increased the distance migrated from a mean of $20 \pm 15 \mu \mathrm{m}$ ( with a single step of $1-10 \mathrm{nM}$ FMLP) to $71 \pm 16$ $\mu \mathrm{m}$ over the observation period $(P<0.01, n=5$ separate experiments with $25-30$ cells analyzed per experiment). Step increases of $33 \%$ at 200 -s intervals almost completely inhibited detachment, and increased migration to a mean of $173 \pm 35 \mu \mathrm{m}$ $(P<0.01, n=5$ separate experiments with $25-30$ cells analyzed per experiment). If the intervals between steps in [FMLP] were lengthened to $400 \mathrm{~s}$, many cells detached before the next [FMLP] was introduced (data not shown).

Extracellular calcium is needed for Mac-1-dependent neutrophil locomotion. A possible role for extracellular $\mathrm{Ca}^{++}$in Mac-1-dependent neutrophil locomotion was suggested by the studies of Berger et al. (8). They have shown that extracellular $\mathrm{Ca}^{++}$is needed for optimum up-regulation of Mac-1. In order to confirm that this is true following a change in the [FMLP], neutrophils after the initial stimulus were washed and maintained in $\mathrm{Ca}^{++}$-free PBS. As shown in Fig. 8, mobilization of 

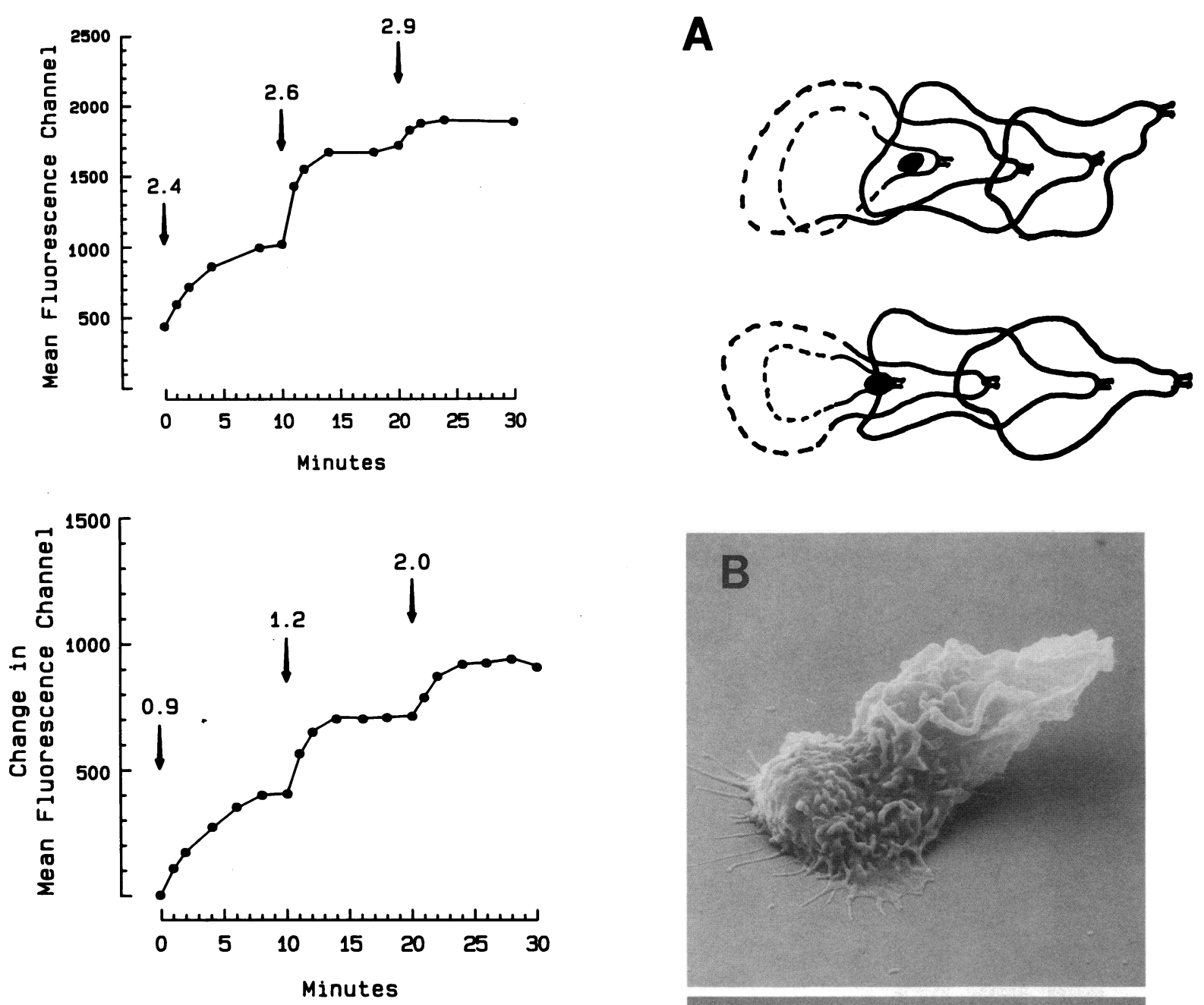

Figure 4. Kinetic study of the increases in surface Mac-1 after increases in [FMLP]. Isolated neutrophils were suspended in PBS containing $30 \mu \mathrm{g} / \mathrm{ml}$ of PE-labeled anti-CD1 $1 \mathrm{~b} \mathrm{mAb}$ (Leu-15, upper graph; 2LPM19c, lower graph) and incubated for $3 \mathrm{~min}$. Sufficient FMLP was added to the cell suspension to attain the final concentration $(\mathrm{nM})$ shown, and cells $(3,000)$ were repeatedly sampled directly for flow cytometry. At 10 and at $20 \mathrm{~min}$ the [FMLP] was increased as shown. These data are from studies with two donors, and are representative of results with cells from five separate donors.

Mac-1 after an additional step increase in [FMLP] was significantly reduced when extracellular $\mathrm{Ca}^{++}$was removed.

The need for extracellular $\mathrm{Ca}^{++}$in the movement of ACLB over the cell surface was also evaluated. Though the removal of extracellular $\mathrm{Ca}^{++}$does not affect the neutrophil's ability to develop a bipolar shape after exposure to a chemotactic stimulus (23), the movement of ACLB to the uropod was significantly reduced in $\mathrm{Ca}^{++}$-free PBS (Table I). In the assay of Mac-1-dependent cell locomotion, using $\mathrm{Ca}^{++}$-free PBS revealed that after multiple stepwise increments in [FMLP] where each step was $33 \%$ higher than the previous concentration (i.e., the same protocol used in Fig. 7), the migration path was a mean of $51 \pm 4 \mu \mathrm{m}(n=5)$. This is a significantly reduced value when compared with migration under $\mathrm{Ca}^{++}$sufficient conditions $(P<0.01)$ over the same observation period.

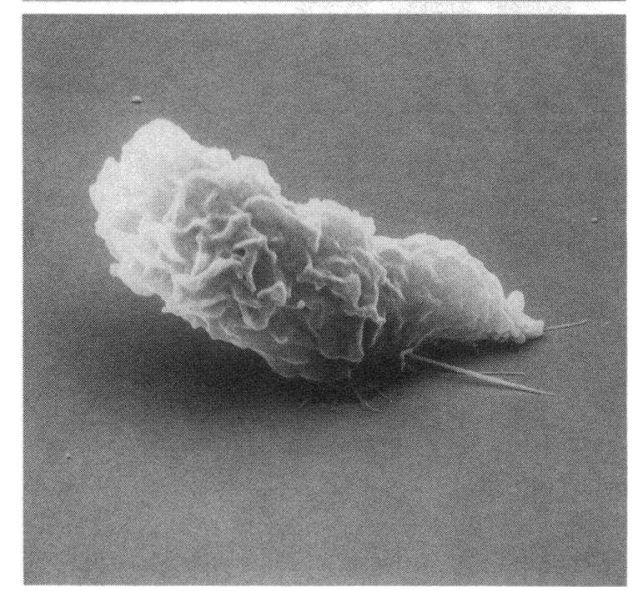

Figure 5. Neutrophil detachment from protein-coated glass. Isolated neutrophils hanging from the upper wall of a parallel plate flow chamber were exposed to a single step in [FMLP] from 0.3 to $1.0 \mathrm{nM}$. ( $A$ ) A frequently observed behavior is depicted by tracings of the outlines of cells moving right to left over a 10 -min observation period. Video recordings were made under phase contrast microscopy $(\times 100$ objective, focal plane was that of the tip of the uropod). The dotted line indicates portions of the cell out of focus and the dark spot indicates the position of the attached uropod when the cell was hanging from the surface. $(B)$ At 10 min after the second stimulus, the cells were fixed and processed for scanning electron microscopy. Two representative cells showing different degrees of detachment are shown. 


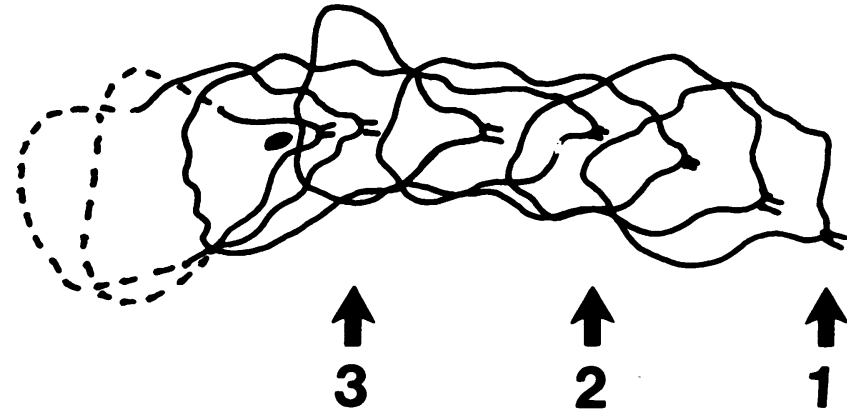

Figure 6. Effects of stepwise increases in [FMLP] on adherence-dependent migration of isolated neutrophils. Neutrophils hanging from the upper wall of a parallel plate flow chamber were exposed to three steps (1) from 0.3 to $2.4 \mathrm{nM}$, (2) from 2.4 to $3.2 \mathrm{nM}$, and (3) from 3.2 to $4.3 \mathrm{nM}$ at $200-\mathrm{s}$ intervals. The fluid in the chamber was stationary after each new [FMLP] was attained. A frequently observed behavior is depicted by tracings of the outlines of a cell moving right to left over a 15-min observation period. Video recordings were made under phase-contrast microscopy $(\times 100$ objective, focal plane was that of the tip of the uropod). The dotted line indicates portions of the cell out of focus and the dark spot indicates the position of the attached uropod when the cell was hanging from the surface.

\section{Discussion}

Several published reports using sustained, saturating concentrations of stimuli (i.e., conditions that inhibit neutrophil locomotion ) demonstrated that the newly mobilized Mac-1 did not contribute to the adhesive events provoked by the stimulus. Why the newly arrived Mac-1 does not participate in the coincident adhesive events is unknown. Three general possibilities are readily apparent: $(a)$ The stored Mac-1 is incapable of functioning in adhesion. $(b)$ There is a temporal dissociation, i.e.,

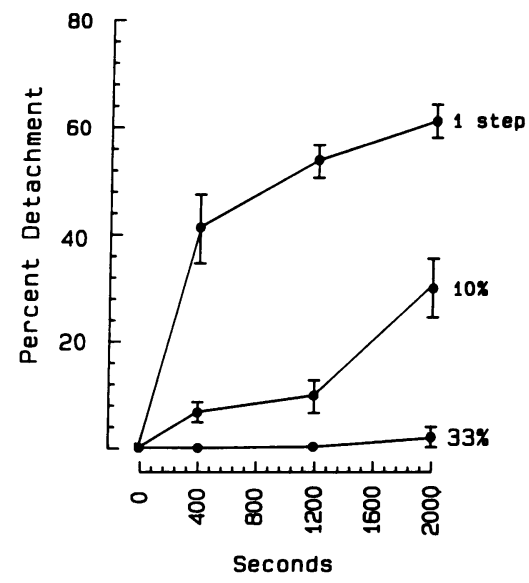

Figure 7. Effects of stepwise increases in [FMLP] on detachment of neutrophils from a protein-coated glass surface. Neutrophils hanging from the upper wall of a parallel plate flow chamber were exposed to a single step or to multiple step increases in [FMLP]. The chamber volume was exchanged every $200 \mathrm{~s}$, but the fluid in the chamber was stationary between each exchange. The percentage of cell detachment at the times indicated was determined during three experimental conditions: a single step increase from 1 to $10 \mathrm{nM}$ FMLP occurring at the first exchange, with subsequent exchanges maintaining the $10 \mathrm{nM}$ concentration; step increases in [FMLP] of $10 \%$; and step increases in [FMLP] of 33\%. Results are given as mean \pm SD for five separate experiments. All values for detachment of cells exposed to increasing [FMLP] were significantly different $(P<0.01)$ from the single-step condition.

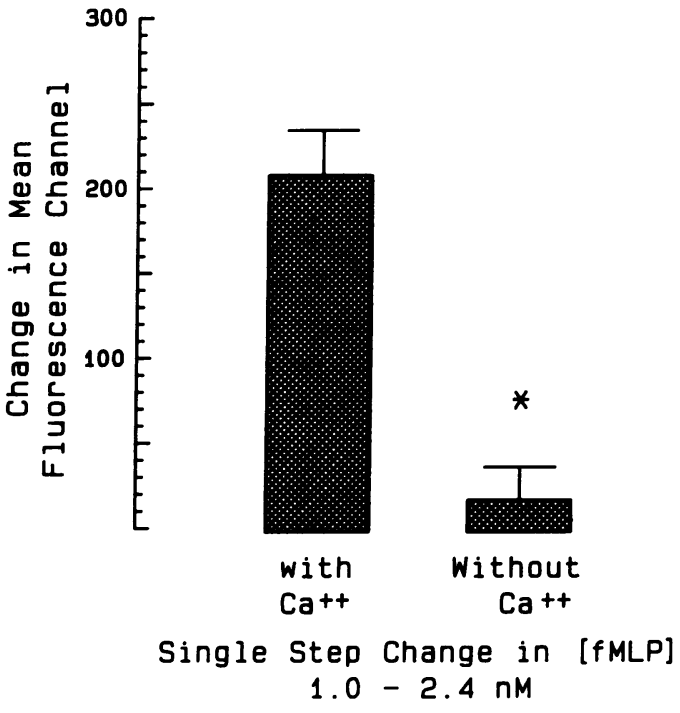

Figure 8. Effect of a single-step change in [FMLP] on the binding of $\mathrm{mAb} 904$ to isolated human neutrophils, requirement for extracellular $\mathrm{Ca}^{++}$. The experimental conditions were the same as described in Fig. 3 with the exception that cells were resuspended in $\mathrm{Ca}^{++}$-free PBS containing $1 \mathrm{mM}$ EGTA immediately before increasing [FMLP] to $2.4 \mathrm{nM}$. The mean increase in cell-associated PE fluorescence is plotted. The results are given as mean $\pm \mathrm{SD}$ for five separate experiments. ${ }^{*} P<0.01$.

the activation event is so rapid that it precedes the arrival of Mac-1 from the intracellular pools, but once present at the surface, the new Mac- 1 is potentially functional. A dissociation between adhesion and arrival of new Mac-1 was seen by Phillips et al. (15). (c) The translocated Mac-1 must undergo some change after it arrives at the cell surface before it can be acti-

Table I. Need for Extracellular $\mathrm{Ca}^{++}$in the Transport of Surface-bound ACLB to the Neutrophil Uropod

\begin{tabular}{|c|c|c|}
\hline \multirow[b]{2}{*}{ Experimental conditions* } & \multicolumn{2}{|c|}{ ACLB distribution } \\
\hline & Random & Uropod \\
\hline PBS, 1 nM FMLP & $91 \pm 3$ & $4 \pm 1$ \\
\hline PBS, $1-10$ nM FMLP & $14 \pm 2$ & $84 \pm 2^{\ddagger}$ \\
\hline \multicolumn{3}{|l|}{$\mathrm{Ca}^{++}$-free PBS, } \\
\hline 1 nM FMLP & $90 \pm 2$ & $2 \pm 2$ \\
\hline \multicolumn{3}{|l|}{$\mathrm{Ca}^{++}$-free PBS, } \\
\hline 1-10 nM FMLP & $82 \pm 1$ & $12 \pm 3^{\S}$ \\
\hline
\end{tabular}

* Isolated neutrophils were suspended in PBS containing ACLB and 1 nM FMLP for $5 \mathrm{~min}$, and then washed in either PBS containing 1 nM FMLP or $\mathrm{Ca}^{++}$free PBS containing $1 \mathrm{mM}$ EGTA and $1 \mathrm{nM}$ FMLP. The washed cells were either fixed in flutaraldehyde or exposed to an increase in [FMLP] to $10 \mathrm{nM}$. The distribution of surface-bound ACLB was then evaluated, and cells categorized into three groups, those with ACLB randomly distributed on the cell surface, those with ACLB only on the uropod, and those without surface bound ACLB

${ }^{\ddagger} P<0.01$ compared with PBS and 1 nM FMLP.

${ }^{5} P<0.01$ compared with PBS and $1-10$ nM FMLP. 
vated, and this change is not complete until after the events that activate the constitutive Mac-1 have waned. Though the nature of such a change is not apparent, evidence for structural changes in Mac-1 is provided by recent studies indicating some regulatory control over the Mac-1 present at the cell surface. Detmers et al. (18) found an association of increased Mac-1 function with ultrastructural evidence of transient clustering of surface Mac-1, and speculated that such clustering would contribute to the increased strength of adhesion. Dransfield and Hogg (28) identified a monoclonal antibody that recognizes what appears to be an activated state of Mac-1, suggesting that this heterodimer undergoes a structural change associated with its ability to function in adhesion.

Our results indicate that the newly mobilized Mac-1 is capable of functioning in adhesion only if cells are subsequently exposed to an additional stimulus level. The time needed for this change and the nature of the change are the subjects of future studies, but it is reasonable to assume that the sustained migration of neutrophils under conditions where adhesion was Mac-1-dependent (Fig. 7) was linked to the ability of newly mobilized Mac-1 to function in adhesion following each stimulus increment. In this model, steps in [FMLP] serve two functions, to induce adherence through the surface Mac-1, and to mobilize stored Mac-1 that can be activated when the stimulus concentration increases again. Studies of migrating neutrophils by Francis et al. (29) are consistent with the hypothesis that the intracellular pools replenish surface Mac-1 that is transported to the uropod and filopodia during migration. Using rhodamine- and fluorescein-labeled anti-CD11b antibodies they were able to clearly show a polarized distribution of CD11b/ CD18 on migrating cells, with newly expressed CD11b/CD18 at the leading edge of the migrating cell. Our results suggest that this newly expressed CD11b/CD18 is subsequently used during adherence-dependent migration.

In the present studies we found that small increases in [FMLP] augmented CD11b/CD18 (Mac-1)-dependent adhesion and translocated Mac-1 from intracellular stores to the cell surface. These events occurred repeatedly in the same population of neutrophils exposed to sequential stepwise increases in [FMLP] over a concentration range known to promote optimal orientation and chemotactic migration. Under circumstances where cell locomotion was principally dependent on Mac-1 adhesion, cell migration was maintained only when [FMLP] was periodically increased. Otherwise, in the presence of a constant [FMLP], a high percentage of neutrophils detached after a short migration path. These results indicate that following stimulation, Mac-1-dependent adhesion was only briefly augmented. Translocation of Mac-1 from intracellular stores also appeared to be briefly promoted by steps in [FMLP], in that the increase in surface levels appeared to plateau within a few minutes after each stimulus increment. Thus, there appears to be a qualitative and quantitative relationship between the stimulus level and the observed changes in surface Mac-1.

Chemotactic factors, therefore, induce changes in the amount and function of CD1 $1 \mathrm{~b} / \mathrm{CD} 18$ adhesive events necessary for locomotion on a flat protein-coated substratum, and these changes may contribute to directional migration in a chemotactic gradient. A spatial chemotactic gradient appears to bias the cell's first pseudopod toward the higher concentration of chemotactic factor (30), but a temporal mechanism may operate in the cell's continued sensing of a gradient (31). Over time, there appears to be an adaptive response to a stimulus concentration (32), after which an increase leads to pseudopod formation (32), and as we have shown, new Mac-1 adhesion sites. A decrease results in pseudopod withdrawal (32), and as we have found, in failure to form Mac-1-dependent adhesion. Under conditions where neutrophil migration depends on Mac-1, directional migration may depend on mobilization of Mac-1 from intracellular pools.

Marks and Maxfield (33) have presented data that neutrophils in $\mathrm{C} \mathrm{Ca}^{++}$free incubation medium failed to migrate, though the cells exhibited the capacity to spread and assume the bipolar shape characteristic of migrating cells. These authors provided visual evidence of these phenomena and speculated that cellular attachment to the substratum was of sufficient strength to tether the cells thereby preventing migration. In such a model $\left[\mathrm{Ca}^{++}\right]_{\mathrm{i}}$ transients would be required to free the cells from the anchor so that locomotion could proceed. Our observations indicate that Mac-1-dependent migration is also sensitive to depletion of extracellular $\mathrm{Ca}^{++}$, and indicate that extracellular $\mathrm{Ca}^{++}$is needed for both mobilization of Mac1 from intracellular pools following increases in chemotactic stimulation and transport of adhesion sites to the tail of a polarized neutrophil. While $\left[\mathrm{Ca}^{++}\right]_{\mathrm{i}}$ transients may not be needed for movement of neutrophils under some conditions (34), Marks et al. (35) have recently shown that the dependency of neutrophil locomotion on extracellular $\mathrm{Ca}^{++}$is in some still poorly defined way influenced by adhesive factors. Jaconi et al. (36) provided evidence that Mac-1-mediated adhesion of neutrophils generates multiple $\left[\mathrm{Ca}^{++}\right]_{\mathrm{i}}$ transients that may control events associated with cell movement.

Transendothelial migration of neutrophils in response to a gradient of chemotactic factors across a confluent monolayer of endothelial cells can be readily shown in vitro. Furie et al. (37) have recently shown that this migration involves Mac-1. The significance of Mac- 1 to transendothelial migration in vivo has been shown in two settings. Patients with secondary granule deficiency, and therefore, a marked reduction in the intracellular pool of Mac-1, exhibited no increase in surface Mac-1 after chemotactic stimulation and poor migration of neutrophils into sites of inflammation (38-41). In animal models, anti-CD1 lb mAbs have been found to reduce the accumulation of neutrophils at some inflammatory sites. Jutila et al. (42), demonstrated that anti-CD1 $1 \mathrm{~b}$ reduced the migration of neutrophils into the peritoneal cavity of mice by $>60 \%$. Rosen and Gordon (43) demonstrated that anti-CD11b mAb 5C6 produced $83 \%$ inhibition of neutrophil influx in thioglycollate induced peritoneal inflammation in mice. mAb 5C6 was also found to be effective in reducing the neutrophil extravasation in mouse lungs induced by intratracheal administration of lipopolysaccharide (44). Jaeschke et al. (45) found that in a mouse model of endotoxin-induced liver necrosis, anti-CD11 b mAb administration was almost as effective as an anti-CD18 mAb in reducing the number of neutrophils in the liver. Such studies along with those in the present report support the hypothesis that Mac-1 plays an important role in extravasation of neutrophils by contributing to the motility of the cell, and that mobilization of Mac-1 from intracellular pools is used in this process.

Recent studies of transendothelial migration have provided evidence, however, that Mac-1 is not the only $\beta 2$-integrin involved in neutrophil locomotion. Transmigration induced by 
cytokine stimulation of endothelial cell monolayers was reduced much more effectively by mAbs to CD1 1a or to ICAM-1 than by mAbs to CD11b (even mAbs that produced marked reduction in neutrophil migration on protein-coated glass or plastic, e.g., 904) (3, 46). Furie et al. (37) found that migration of neutrophils through confluent monolayers of endothelial cells (without cytokine stimulation) toward a gradient of chemotactic factors (e.g., FMLP), is also more effectively blocked by anti-CD11a or anti-ICAM-1 mAbs than anti-CD11b mAbs. Such studies support the conclusion that LFA-1 functions in the locomotion of neutrophils and utilizes one of its known ligands, endothelial ICAM-1. T cells also appear to utilize LFA-1 and ICAM-1 in the process of transendothelial migration $(47,48)$. This is of interest because there is no known rapidly mobilizable intracellular pool of LFA- 1 in either neutrophils or lymphocytes. LFA-1 appears to be constitutively expressed on these cells, and chemotactic stimulation causes very little to no increase in the amount of this integrin on the cell surface. The neutrophil thus appears to possess multiple mechanisms for stimulated locomotion that are apparently influenced by the molecules needed for adherence to a particular substrate.

\section{Acknowledgments}

The expert secretarial assistance of Michelle Swarthout and Irene Harrison is acknowledged.

These studies were supported in part by grants AI-19031, AI-23521, and HL-42550 from the National Institutes of Health and a grant from Boehringer Ingelheim Pharmaceuticals, Inc.

\section{References}

1. Schmalstieg, F. C., H. E. Rudloff, G. R. Hillman, and D. C. Anderson 1986. Two dimensional and three dimensional movement of human polymorphonuclear leukocytes: two fundamentally different mechanisms of locomotion. J. Leukocyte Biol. 40:677-691.

2. Smith, C. W., R. Rothlein, B. J. Hughes, M. M. Mariscalco, F. C. Schmalstieg, and D. C. Anderson. 1988. Recognition of an endothelial determinant for CD18-dependent human neutrophil adherence and transendothelial migration. J. Clin. Invest. 82:1746-1756.

3. Smith, C. W., S. D. Marlin, R. Rothlein, C. Toman, and D. C. Anderson 1989. Cooperative interactions of LFA-1 and Mac-1 with intercellular adhesion molecule- 1 in facilitating adherence and transendothelial migration of human neutrophils in vitro. J. Clin. Invest. 83:2008-2017.

4. Anderson, D. C., L. J. Miller, F. C. Schmalstieg, R. Rothlein, and T. A. Springer. 1986. Contributions of the Mac-1 glycoprotein family to adherence-dependent granulocyte functions: structure-function assessments employing subunit-specific monoclonal antibodies. J. Immunol. 137:15-27.

5. Wright, S. D., and M. T. C. Jong. 1986. Adhesion-promoting receptors on human macrophages recognize Escherichia coli by binding to lipopolysaccharide. J. Exp. Med. 164:1876-1888.

6. Wright, S. D., S. M. Levin, M. T. C. Jong, Z. Chad, and L. G. Kabbash. 1989. CR3 (CD1 1b/CD18) expresses one binding site for Arg-Gly-Asp-containing peptides and a second site for bacterial lipopolysaccharide. J. Exp. Med. 169:175-183.

7. Wright, S. D., S. K. Lo, and P. A. Detmers. 1989. Specificity and regulation of CD18-dependent adhesion. In Leukocyte Adhesion Molecules: Structure, Function and Regulation. T. A. Springer, D. C. Anderson, R. Rothlein, and A. S. Rosenthal, editors. Springer-Verlag, Inc., New York. 190-207.

8. Berger, M., J. J. O'Shea, A. S. Cross, T. M. Folks, T. M. Chused, E. J. Brown, and M. M. Frank. 1984. Human neutrophils increase expression of C3bi as well as C3b receptors upon activation. J. Clin. Invest. 74:1566-1571.

9. Todd, III, R. F., M. A. Arnaout, R. E. Rosin, C. A. Crowley, W. A. Peters, and B. M. Babior. 1984. Subcellular localization of the large subunit of Mol ( $\mathrm{Mol}_{1}$; formerly gpl 10), a surface glycoprotein associated with neutrophil adhesion. J. Clin. Invest. 74:1280-1290.

10. Jones, D. H., F. C. Schmalstieg, H. K. Hawkins, B. L. Burr, H. E. Rudloff, S. S. Krater, C. W. Smith, and D. C. Anderson. 1989. Characterization of a new mobilizable Mac-1 (CD11b/CD18) pool that co-localizes with gelatinase in human neutrophils. In Leukocyte Adhesion Molecules: Structure, Function, and
Regulation. T. A. Springer, D. C. Anderson, A. S. Rosenthal, and R. Rothlein, editors. Springer-Verlag, Inc., New York. 106-124.

11. Petty, H. R., J. W. Francis, III, R. F. Todd, P. R. Petrequin, and L. A. Boxer. 1987. Neutrophil C3bi receptors: formation of membrane clusters during cell triggering requires intracellular granules. J. Cell. Physiol. 133:235-242.

12. Boxer, L. A., R. A. Haak, H.-H. Yang, J. B. Wolach, J. A. Whitcomb, C. H. Butterick, and R. L. Baehner. 1982. Membrane-bound lactoferrin alters the surface properties of polymorphonuclear leukocytes. J. Clin. Invest. 70:10491057.

13. Oseas, R., H.-H. Yang, R. L. Baehner, and L. A. Boxer. 1981. Lactoferrin: a promoter of polymorphonuclear leukocyte adhesiveness. Blood. 57:939-945.

14. Bainton, D. F., L. J. Miller, T. K. Kishimoto, and T. A. Springer. 1987 Leukocyte adhesion receptors are stored in peroxidase-negative granules of human neutrophils. J. Exp. Med. 166:1641-1653.

15. Phillips, M. R., J. P. Buyon, R. Winchester, G. Weissmann, and S. B. Abramson. 1988. Up-regulation of the iC3b receptor (CR3) is neither necessary nor sufficient to promote neutrophil aggregation. J. Clin. Invest. 82:495-501.

16. Buyon, J. P., S. B. Abramson, M. R. Philips, S. G. Slade, G. D. Ross, G. Weissmann, and R. J. Winchester. 1988. Dissociation between increased surface expression of Gp165/95 and homotypic neutrophil aggregation. J. Immunol. 140:3156-3160.

17. Buyon, J. P., S. G. Slade, J. Reibman, S. B. Abramson, M. R. Philips, G. Weissman, and R. Winchester. 1990. Constitutive and induced phosphorylation of the alpha and beta-chains of the CD11/CD18 leukocyte integrin family. $J$. Immunol. 144:191-197.

18. Detmers, P. A., S. D. Wright, E. Olsen, B. Kimball, and Z. A. Cohn. 1987. Aggregation of complement receptors on human neutrophils in the absence of ligand. J. Cell Biol. 105:1137-1145.

19. Vedder, N. B., and J. M. Harlan. 1988. Increased surface expression of $\mathrm{CD} 1 \mathrm{lb} / \mathrm{CD} 18$ (Mac-1) is not required for stimulated neutrophil adherence to cultured endothelium. J. Clin. Invest. 81:676-682.

20. Smith, C. W., T. K. Kishimoto, O. Abbassi, B. J. Hughes, R. Rothlein, L. V. McIntire, E. Butcher, and D. C. Anderson. 1991. Chemotactic factors regulate lectin adhesion molecule 1 (LECAM-1)-dependent neutrophil adhesion to cytokine-stimulated endothelial cells in vitro. J. Clin. Invest. 87:609-618.

21. Entman, M. L., K. Youker, S. B. Shappell, C. Siegel, R. Rothlein, W. J. Dreyer, F. C. Schmalstieg, and C. W. Smith. 1990. Neutrophil adherence to isolated adult canine myocytes: evidence for a CD18-dependent mechanism. $J$. Clin. Invest. 85:1497-1506.

22. Miller, L. J., D. F. Bainton, N. Borregaard, and T. A. Springer. 1987. Stimulated mobilization of monocyte Mac-1 and p150,95 adhesion proteins from an intracellular vesicular compartment to the cell surface. J. Clin. Invest. 80:535-544.

23. Smith, C. W., J. C. Hollers, R. A. Patrick, and C. Hassett. 1979. Motility and adhesiveness in human neutrophils: effects of chemotactic factors. J. Clin. Invest. 63:221-229.

24. Shappell, S. B., C. Toman, D. C. Anderson, A. A. Taylor, M. L. Entman, and C. W. Smith. 1990. Mac-1 (CD1 1b/CD18) mediates adherence-dependent hydrogen peroxide production by human and canine neutrophils. J. Immunol. 144:2702-2711.

25. Smith, C. W., and J. C. Hollers. 1980. Motility and adhesiveness in human neutrophils. Redistribution of chemotactic factor induced adhesion sites. J. Clin. Invest. 65:804-812.

26. Anderson, D. C., B. J. Hughes, and C. W. Smith. 1981. Abnormal mobility of neonatal polymorphonuclear leukocytes: relationship to impaired redistribution of surface adhesion sites by chemotactic factor or colchicine. J. Clin. Invest. 68:863-874.

27. Zigmond, S. H. 1978. Chemotaxis by polymorphonuclear leukocytes. $J$. Cell Biol. 77:269-287.

28. Dransfield, I., and N. Hogg. 1989. Regulated expression of $\mathrm{Mg}^{2+}$ binding epitope on leukocyte integrin alpha subunits. EMBO (Eur. Mol. Biol. Organ.) J. 8:3759-3765.

29. Francis, J. W., R. F. Todd, L. A. Boxer, and H. R. Petty. 1989. Sequentia expression of cell surface $\mathrm{C} 3 \mathrm{bi}$ receptors during neutrophil locomotion. J. Cell. Physiol. 140:519-523.

30. Zigmond, S. H. 1977. Ability of polymorphonuclear leukocytes to orient in gradients of chemotactic factors. J. Cell Biol. 75:606-616.

31. Tranquillo, R. T., D. A. Lauffenburger, and S. H. Zigmond. 1988. A stochastic model for leukocyte random motility and chemotaxis based on receptor binding fluctuations. J. Cell Biol. 106:303-309.

32. Zigmond, S. H., and S. J. Sullivan. 1979. Sensory adaptation of leukocytes to chemotactic peptides. J. Cell Biol. 82:517-527.

33. Marks, P. W., and F. R. Maxfield. 1990. Transient increases in cytosolic free calcium appear to be required for the migration of adherent human neutrophils. J. Cell Biol. 110:43-52.

34. Zigmond, S. H., J. L. Slonczewski, M. W. Wilde, and M. Carson. 1988. Polymorphonuclear leukocyte locomotion is insensitive to lowered cytophasmic calcium levels. Cell Motil. Cytoskeleton. 9:184-189. 
35. Marks, P. W., B. Hendey, and F. R. Maxfield. 1991. Attachment to fibronectin or vitronectin makes human neutrophil migration sensitive to alterations in cytosolic free calcium concentration. J. Cell Biol. 112:149-158.

36. Jaconi, M. E. E., J. M. Theler, W. Schlegel, R. D. Appel, S. D. Wright, and R. D. Lew. 1991. Multiple elevations of cytosolic-free $\mathrm{Ca}^{2+}$ in human neutrophils: initiation by adherence receptors of the integrin family. J. Cell Biol. 112:1249-1257.

37. Furie, M. B., M. C. A. Tancinco, and C. W. Smith. 1991. Monoclonal antibodies to leukocyte integrins $\mathrm{CD} 11 \mathrm{a} / \mathrm{CD} 18$ and $\mathrm{CD} 1 \mathrm{lb} / \mathrm{CD} 18$ or intercellular adhesion molecule-1 (ICAM-1) inhibit chemoattractant-stimulated neutrophil transendothelial migration in vitro. Blood. 78:2089-2097.

38. Boxer, L. A., T. D. Coates, R. A. Haak, J. B. Wolach, S. Hoffstein, and R. L. Baehner. 1982. Lactoferrin deficiency associated granulocyte function. $N$. Engl. J. Med. 307:404-410.

39. Gallin, J. I., M. P. Fletcher, B. E. Seligmann, S. Hoffstein, K. Cehr, and N. Mounessa. 1982. Human neutrophil-specific granules deficiency: a method to access the role of neutrophil-specific granules in the evolution of the inflammatory response. Blood. 59:1317-1329.

40. O'Shea, J. J., E. J. Brown, B. E. Seligmann, J. A. Metcalf, M. M. Frank, and J. I. Gallin. 1985. Evidence for distinct intracellular pools of receptors for C3b and C3bi in human neutrophils. J. Immunol. 134:2580-2587.

41. Petrequin, P. R., III, R. F. Todd, J. E. Smolen, and L. A. Boxer. 1986 Expression of specific granule markers on the cell surface of neutrophil cytoplasts. Blood. 67:1119-1125.
42. Jutila, M. A., L. Rott, E. L. Berg, and E. C. Butcher. 1989. Function and regulation of the neutrophil MEL-14 antigen in vivo: comparison with LFA-1 and MAC-1. J. Immunol. 143:3318-3324.

43. Rosen, H., and S. Gordon. 1987. Monoclonal antibody to the murine type 3 complement receptor inhibits adhesion of myelomonocytic cells in vitro and inflammatory cell recruitment in vivo. J. Exp. Med. 166:1685-1701.

44. Rosen, H. 1990. Role of CR3 in induced myelomonocytic recruitment: insights from in vivo monoclonal antibody studies in the mouse. J. Leukocyte Biol. 48:465-469.

45. Jaeschke, H., A. I. Farhood, and C. W. Smith. 1991. Neutrophil-induced liver cell injury in endotoxin shock is a CD11b/CD18-dependent mechanism. Am. J. Physiol. 261:C1051-C1056.

46. Anderson, D. C., R. Rothlein, S. D. Marlin, S. S. Krater, and C. W. Smith. 1990. Impaired Transendothelial migration by neonatal neutrophils: abnormalities of Mac-1 (CD1 lb/CD18)-dependent adherence reactions. Blood. 78:26132621.

47. Van Epps, D. E., J. Potter, M. Vachual, C. W. Smith, and D. C. Anderson. 1989. Suppression of human lymphocyte chemotaxis and transendothelial migration of anti-LFA-1 antibody. J. Immunol. 143:3207-3210.

48. Oppenheimer-Marks, N., L. S. Davis, D. T. Bogue, J. Ramberg, and R. E. Lipsky. 1991. Differential utilization of ICAM-1 and VCAM-1 during adhesion and transendothelial migration of human $\mathrm{T}$ lymphocytes. J. Immunol. 147:2913-2921 